\title{
Neonatal Alloimmune Neutropenia
}

\author{
Leendert Porcelijn $^{a}$ Masja de Haas ${ }^{a, b, c}$ \\ a Immunohematology Diagnostic Services, Sanquin Diagnostic Services, Amsterdam, the Netherlands; \\ ${ }^{b}$ Department of Immuno-Hematology and Blood Transfusion, Leiden University Medical Center, Leiden, the Netherlands; \\ ${ }^{\mathrm{c}}$ Center for Clinical Transfusion Research, Sanquin Research, Leiden, the Netherlands
}

\section{Keywords}

Fetal alloimmune thrombocytopenia - Hemolytic disease of the newborn - Neonatal alloimmune neutropenia

\section{Summary}

Neonatal alloimmune neutropenia (NAIN, NAIN or NIN) is a neutrophil blood group antagonism, analogous to hemolytic disease of the fetus and newborn (HDFN) and fetal/neonatal alloimmune thrombocytopenia (FNAIT). A limited number of prospective screening studies showed that granulocyte-specific antibodies were detectable in $0.35-1.1 \%$ of random postnatal maternal samples and that the incidence of NAIN was below $0.1 \%$. Symptoms vary from none to mild skin infections, omphalitis or more severe infections like pneumonia, sepsis, and meningitis. Treatment of neonatal infection with antibiotics and granulocyte-colony stimulating factor is advised.

\section{(c) 2018 The Author(s)}

Published by S. Karger GmbH, Freiburg
8 days postpartum, which was treated with antibiotics. Her neutrophil count did not respond to corticosteroids, but normalized after 71 days. Total leukocyte counts in the children were normal, as the severe neutropenia was compensated by a monocytosis.

Already this early report very well characterizes neonatal alloimmune neutropenia [3]. In this disease, the mother has developed alloantibodies against a certain neutrophil antigen, which the fetus inherits from the father. In this particular case, the father had been heterozygous for the antigen in question, explaining the unaffected second child. Shortly after this report, the first detected neutrophil antigens were described and named NA1, NA2 and NB1 $[4,5]$. Analogous to the PLA nomenclature for platelet antigens, proposed by Shulman, the name was composed of the N, for neutrophil specificity, the A, B etc. for the order the antigen system (genetic locus) was detected, and the numbers to identify alleles [4]. In 1998 , this nomenclature was changed to the currently used human neutrophil antigen (HNA) system and updated in 2015 [6, 7]. Currently, 11 HNAs within five different HNA systems are known: four HNA-1 alleles, HNA-2, two HNA-3, two HNA-4 alleles, and two HNA-5 alleles (table 1) [7]. For the detection of the anti-neutrophil antibodies, Lalezari and Spaet [8] used the leukoagglutination technique. This technique is still being used, especially for the detection of anti-HNA-3 antibodies [9]. However, in the 1970s and 1980s the granulocyte immunofluorescence test (GIFT) [10] and monoclonal antibody immobilization of granulocyte antigens (MAIGA) [11] became available, and recently bead-based antibody detection methods have been developed $[12,13]$.

There may be some confusion about which name can best be used for this condition. We decided to use in this review the name fetal/neonatal alloimmune neutropenia (FNAIN), analogous to fetal/neonatal alloimmune thrombocytopenia (FNAIT), which is commonly used for the platelet antagonism, and not isoimmune neonatal neutropenia. Furthermore, in this paper we shortened FNAIN to neonatal alloimmune neutropenia (NAIN), as it is actually unknown if already the fetal neutrophil count is affected and mately 70 days postpartum. The fourth child developed omphalitis

\section{KARGER}

Fax +497614520714 Information@Karger.com www.karger.com

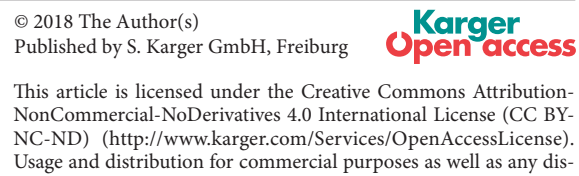
tribution of modified material requires written permission.

After several reports [1, 2] of siblings suspected for immune mediated agranulocytosis in the 1950s, it was in 1960 that Lalezari severe neutropenia (complete absence of granulocytes) in three of penia'. Unfortunately, the first child died of pneumonia. After an unaffected second child, the third child developed severe scalp inflammation and possibly sepsis 8 days postpartum. She was treated 


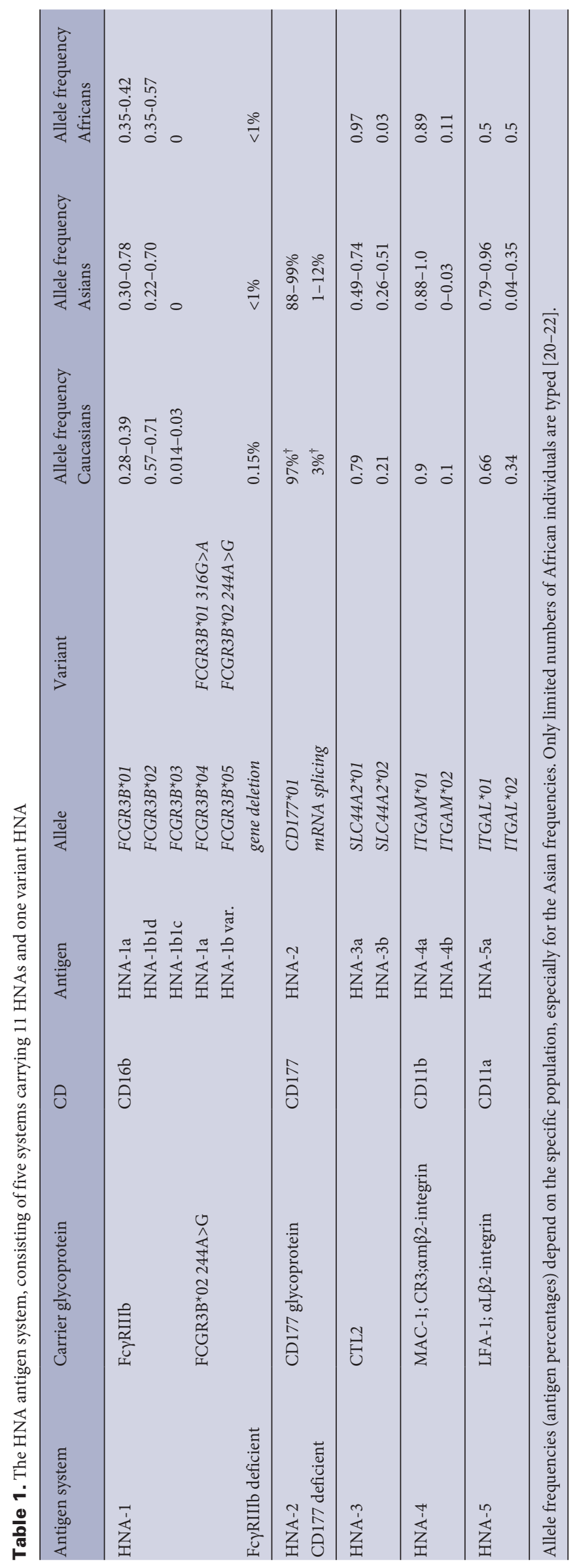

because the clinical symptoms are, in contrast to FNAIT, not already present in the fetus. Neonatal immune neutropenia (NIN) is mostly due to maternal alloantibodies directed to the non-self-fetal (paternal) neutrophil-specific antigens. Rarely, in cases of maternal autoimmune neutropenia, maternal neutrophil specific autoantibodies of the IgG class can cause neonatal neutropenia [14]. In this overview we therefore, focus on the NAIN.

\section{Pathology}

NAIN results from maternal sensitization to paternal HNAs present on the fetal neutrophils. The anti-HNA antibodies of the IgG immunoglobulin class are transported across the placenta and bind to the fetal neutrophils. It is unknown whether the antibodies only lead to increased destruction of mature cells or also to inhibition of granulocytopoiesis. In some cases NAIN is caused by isoantibodies, if a mother is lacking a complete HNA system-carrying structure (e.g. anti-Fc $\gamma$ RIIIb isoantibodies or HNA-2 antibodies) [15].

It seems that NAIN can already occur in first pregnancies. In the published series, percentages for NAIN in first pregnancies vary between 5 and $40 \%[4,15,16]$. This implies that maternal immunization can take place during pregnancy or even before the first pregnancy. In our healthy blood donor screening study, we detected anti-Fc $\gamma$ RIIIb antibodies and anti-HNA-1a antibodies of the IgG class in $0.8 \%$ of never allo-exposed (meaning never transfused, organ-transplanted or pregnant) women $[17,18]$. In this study, in healthy blood donors, we did not perform an HNA typing, and, therefore, we do not know if the detected antibodies were auto- or alloantibodies $[17,18]$. Further investigation will be necessary to explain the presence of granulocyte-specific antibodies in never allo-exposed women and primiparous women. Expression of the human platelet antigen 1a (HPA-1a) on glycoprotein $\alpha v \beta 3$ on placental endothelial cells is one of the reasons for alloimmunization against HPA-1a already in the first pregnancy [19]. However, most of the involved granulocyte antigens are not expressed on placental tissue, and therefore, only exposure of these antigens on fetal granulocytes seems to be the immunizing trigger during pregnancy. In table 1, the currently known HNAs and allele frequencies for Caucasians are shown. The allele frequencies vary for Asians, depending on the studied population group. One remarkable difference compared with the Caucasian population is the complete absence of the HNA-1c allele. Only a very limited number of studies have been performed on the allele frequencies in the African population [20-22].

The HNA-1 system is carried by the FcgammaReceptor IIIb $\left(\right.$ Fc $\gamma$ RIIIb) and includes four HNAs: HNA-1a $\left(F C G R 3 B^{*} 01\right)$, HNA-1b, HNA-1c, and HNA-1d. HNA-1c and HNA-1d can only be present in combination with HNA-1b, i.e. HNA1b1c $\left(F C G R 3 B^{\star} 03\right)$ or HNA-1b1d $\left(F C G R 3 B^{\star} 02\right)$. Recently the FCGR $3 B^{\star} 01316 G>A$ and the FCGR3B ${ }^{\star} 02 \quad 244 A>G$ variants were found and named $F C G R 3 B^{\star} 04$ and $F C G R 3 B^{\star} 05$, respectively (table 1) [7, 22-26]. Variation in expression of the HNA-1 alleles is 
possible. About $0.1 \%$ of the population, regardless of which origin, is deficient for Fc $\gamma$ RIIIb, resulting in the HNA-1null phenotype. These individuals can be immunized and produce anti-Fc $\gamma$ RIIIb isoantibodies [27]. Furthermore, individuals can, as a result of gene duplication, have a higher expression of Fc $\gamma$ RIIIb and subsequently be positive for more than two HNA-1 alleles [28-31]. Individuals who are HNA-2-positive mostly also have a CD177(HNA-2)-negative neutrophil subpopulation, due to lack of gene transcription in a subset of the cells $[5,32,33]$. This CD177-negative subpopulation can vary between almost $0 \%$ and almost $100 \%$. HNA-2-negative individuals do not express CD177, as a result of an incorrect splicing process generating premature stop codons and can be immunized against HNA-2 [33-35]. The biallelic HNA-3 system is located on the choline transporter-like protein 2 (CTL2) and includes the HNA-3a and HNA-3b alleles [36, 37]. HNA-4 and HNA-5 are located on the aM subunit (CD11b) and aL (CD11a) of the aMb2 and aLb2 integrins, respectively. HNA-4a, HNA-4b, and HNA-5a result from single nucleotide polymorphisms [38-41]. Maternal sensitization to HNA-1a to HNA-1d, Fc $\gamma$ RIIIb, HNA-2, HNA-3a, HNA-3b, HNA-4a, HNA-4b, and HNA-5a leading to NAIN have all been reported. Most cases are caused by antibodies specific for the Fc $\gamma$ RIIIb located antigens HNA-1a and HNA-1b, followed by anti-HNA-2 and anti-Fc $\gamma$ RIIIb $[3,15,16]$. The other antibody specificities are only rarely detected. Cases of NAIN due to maternal anti-HNA-1c, anti-HNA-1d, anti-HNA-3a, anti-HNA-3b, antiHNA-4b, and anti-HNA-5a antibodies have been described in rare case reports [16, 24, 25, 42-45]. Antibodies against HNA-5b have never been detected.

\section{Incidence}

The incidence of NAIN is not exactly known. Due to the necessary laborious anti-HNA antibody screening and identification assays the known screening studies are limited in size. Furthermore, during the past decades different granulocyte-specific antibody detection techniques were used, and only the antibodies specific for the, at the time of the studies, known HNAs could be identified. It is therefore possible that some antibodies were missed due to incomplete antibody identification panels.

Bux et al. [15] detected 11 (1.1\%) granulocyte-specific antibodies in 1,016 unselected samples postnatally drawn. Four $(0.4 \%)$ of these 11 antibodies, were allogeneic and specific for one of the known HNAs. Zupanska et al. [46] genotyped 1,038 unselected women who had given birth for HNA-1a and HNA-1b and subsequently genotyped the newborns of 490 HNA-1a or HNA-1b homozygous women. Finally they performed an HNA-1 antibody screening for 195 of 203 women who delivered incompatible newborns and detected nine granulocyte-reactive (non-HLA) antibodies (0.9\%), six anti-HNA-1a or HNA-1b and three antibodies with unknown specificity. Interestingly, in both above mentioned studies, none of the newborns delivered by mothers with granulocyte-specific antibodies had signs of infection or neutrophil counts below $1.5 \times 10^{9} / 1$. Han et al. [47] detected three
NAIN cases in 856 neonates $(0.35 \%)$ admitted to neonatal intensive care units in Korea.

In an HLA- and granulocyte-specific antibody screening, we detected specific neutrophil antibodies in 27 of 2,268 (1.2\%) healthy female blood donors $[17,18]$. Nine $(0.8 \%)$ of these antibodies, directed against Fc $\gamma$ RIIIb $(n=5)$ and HNA-1a $(n=4)$, were detected in 1,109 nulliparous never allo-exposed women and 18 (1.6\%), directed against Fc $\gamma$ RIIIb $(n=3), \operatorname{HNA}-1 \mathrm{a}(\mathrm{n}=6), \operatorname{HNA}-1 \mathrm{~b}(\mathrm{n}=3)$, HNA-2 ( $\mathrm{n}=2)$ and HNA-3a $(\mathrm{n}=4)$, in non-transfused primiparous or multiparous women. We did not type the women, and it is likely that the specific neutrophil antibodies, especially in never allo-exposed women, are (partly) autoantibodies, as it is known that neutrophil autoantibodies can be specific for $\mathrm{Fc} \gamma \mathrm{RIIIb}$ and HNA-1a. Furthermore, most pregnancies were already way back longer than 1 year before drawing the blood samples, and antibody levels possibly decreased under the detection levels.

In clinical practice, requests for serological investigation for suspected NAIN for only one in 37,165 newborns are sent to our Sanquin reference laboratory being the only granulocyte serology laboratory in the Netherlands, and NAIN was only diagnosed in one of 118,929 newborns. In our study, this equated to 35 cases over a period of 22.5 years, with approximately 185,000 newborns during each year of the study period [16]. There are a number of explanations for this extremely low detection rate. Firstly, many NAIN cases do not show any symptoms, including the 14 (40\%) of the neonates in our series who did not have any signs of infections but had neutropenia. Secondly, there are other possible causes of neutropenia that make NAIN harder to detect. Thirdly, clinicians may not be aware of the necessity of serological investigations or may consider it unnecessary to perform them. It is advised to diagnose NAIN in order to choose the best prophylactic and/or therapeutic treatment for the neutropenic neonate, to predict the clinical cause, and to anticipate on fetal/neonatal neutropenia in any subsequent children.

\section{Symptoms}

A reduced ANC is mostly already present at birth, but may decrease in the first week post-partum and can last for approximately six months. Most diagnosed NAIN cases, being the cases with clinical symptoms, showed ANCs below 500/ $\mu$ l. A high incidence of miscarriage was reported by Lalezari et al. [4] (19\%) and Bux et al. (50\%) [15]. In our series, 'only' 2 (6\%) of 35 women experienced a miscarriage [16]. It is very likely that in most cases of NAIN (i.e. neutropenia due to maternal neutrophil antibodies) the neonates do not present with infection and/or other clinical symptoms. As already mentioned above, also in our series $14(40 \%)$ of the 35 NAIN cases were detected because cell counts and differentiations were performed for other, non-related, disorders [16]. If symptoms are present, they vary from omphalitis, fever of unknown origin to more severe infections like pneumonia and sepsis $[3,15,16]$. It must be realized that NAIN, causing fulminant infections, can be a potentially fatal condition. Several case reports about severe sepsis 
or meningitis as a result of NAIN have been published [15, 48-50]. As was described in the report of Lalezari et al. [3], infections are not always immediately present, but often start several days after birth. Any early effects of absolute neutrophil count (ANC) on the unborn child have not yet been sufficiently investigated.

\section{Diagnosis}

Neutrophil concentrations for neonates vary considerably in the first week postpartum, with the highest level 6-12 h postpartum $[51,52]$. The concentrations are partly depending on the gestational age, birth weight, gender, and race. Normal blood neutrophil counts for newborns with a birth weight $>1500 \mathrm{~g}$ in the first week

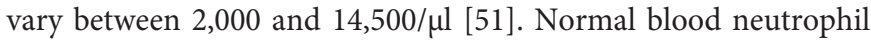
counts for a newborn with a birth weight $<1500 \mathrm{~g}$ can be as low as 500/ $\mu$ l [53]. Schmutz et al. [52] found cord blood ANCs in 30,354 neonates, ranging between 2,700 and $13,000 / \mu$ l for infants born $>36$ weeks gestation, between 1,000 and $12,500 / \mu$ for infants born at 28-36 weeks gestationm and between 1,300 and $15,300 / \mu l$ for infants born at $<28$ weeks gestation. This was measured in a population where ethnic or environmental factors may have been of influence.

The varying neutrophil concentrations may give rise to doubt about when further investigation is needed. Furthermore, ANCs < $1,000 / \mu \mathrm{l}$ is frequently seen at neonatal intensive care units, especially in preterm infants. Neutropenia in a neonate is mostly due to non-immune causes including sepsis, low birth weight, and pregnancy-induced maternal hypertension (table 2) [54-56]. Clinicians should consider further evaluation of neonatal neutropenia if no clear underlying cause is present and/or if the ANC does not increase within 3-5 days. Severe neutropenia $(<500 / \mu \mathrm{l})$ persisting more than 2 days requires additional evaluation [54]. If no maternal granulocyte-reactive antibodies are detected, congenital neutropenia might be present. Bone marrow examination and treatment with recombinant granulocyte-colony stimulating factor $(\mathrm{G}-$ CSF) should then be considered [56].

Serological investigation for cases suspected of NAIN is laborious and needs the availability of HNA-typed donors, equipment and reagents, HNA (geno)typing facilities and skilled experienced technicians. The standard serological work-up for NAIN includes: maternal HNA antibody detection and identification, HNA (geno) typing of both parents and neonate. A cross-match performed with maternal serum and paternal granulocytes is highly recommended.

Several different neutrophil antibody detection/identification methods, of which only the recently developed Luminex beads assays are commercially available, are used [9-13]. It is recommended by the ISBT Working Party on Granulocyte Immunobiology to use the GIFT in combination with the granulocyte agglutination test (GAT) [57]. If possible, the HNA specificity should be confirmed with an antigen-specific assay, such as the monoclonal antibody immobilization of granulocyte antigens (MAIGA) assay [57]. The GIFT is using donor granulocytes, making it necessary to
Table 2. Possible causes for neonatal neutropenia

Pregnancy-induced maternal hypertension/pre-eclampsia
Severe hemolytic disease of the fetus and newborn (HDFN)
Neonatal infection-induced neutropenia
Twin-twin transfusion
Congenital viral infections
Maternal drugs
Neonatal alloimmune neutropenia due to maternal alloantibodies (NAIN)
Neonatal neutropenia due to maternal autoantibodies
Autoimmune neutropenia of infancy

rule out that positive reactions are caused by anti-HLA-class-I antibodies or are due to nonspecific binding of circulating antibodies (immune complexes) via the $\mathrm{Fc}$ tail to the $\mathrm{Fc} \gamma$ receptors. In our laboratory, we test the patient sera before and after absorption of HLA-class-I antibodies using a pool of platelets. The GAT is known to have an enhanced ability to detect granulocyte agglutinins, such as anti-HNA-3a antibodies [57]. The MAIGA assay, a sandwich ELISA, can be used to detect HNA-1 (Fc $\gamma$ RIIIb), panFc $\gamma$ RIIIb, HNA-2 (CD177), HNA-4 (CD11b), and/or HNA-5 (CD11a) antibodies. Until now, no CTL2(HNA-3)-specific monoclonal antibody is available for the MAIGA.

Antigen typing can be done with human antisera; however, nowadays genotyping is the standard procedure. For the different aspects concerning HNA genotyping, we refer to our recently published review [58] on the molecular basis and techniques currently available. Genotyping can be used to predict the HNA phenotype, except HNA-2 negativity. PCR with specific primers (PCR-SSP) is most frequently used; however, a cost-effective high throughput TaqMan assay for the genotyping of HNA-1, HNA-3, HNA-4, and HNA-5 has been developed. The more time-consuming sequencebased typing can be used for distinguish alleles encoding HNA-1a, HNA-1b, HNA-1c, or HNA-1d.

\section{Treatment}

Antibiotics for therapeutic treatment will often be sufficient [59]. Prophylactic treatment with antibiotics can be considered, especially in cases with severe neutropenia $(<500 / \mu l)$. However, evidence on effectiveness is lacking. Treatment with G-CSF is highly effective in increasing neutrophil numbers within days in a majority of cases and can be considered especially for neonates suffering from severe infections [60-62]. One should keep in mind that resistance to G-CSF in NAIN associated with anti-HNA-2 antibodies, possibly due to a G-CSF-induced increase of HNA-2 expression on the neutrophils, has been described [63-65]. Despite the stimulated production of neutrophils, controversial results on the benefit of G-CSF in terms of infection-free survival have been published [66-70].

Some case reports have been published in which benefits for the neonate have been achieved with second-line treatment with intravenous immunoglobulins (IVIg) [71]. However, there is not enough evidence to advice IVIg first-line treatment [72]. 


\section{Conclusion}

Even though NAIN is a relative rare condition, the consequences for the newborn can be serious, and timely diagnosis can prevent severe complications. A good differential diagnosis is important and can point the clinician in the right direction regarding the necessary investigation and treatment, and can predict the clinical course. This can also be reassuring in the counselling of the parents regarding the recovery of their child, and low hazards of severe disease in subsequent pregnancies. Laboratory investigation for detection and specification of the causative maternal granulocyte-specific alloantibodies should be performed by experienced laboratories. In the majority of cases, therapeutic and prophylactic treatment with antibiotics is effective.

\section{Disclosure Statement}

Both authors have no conflict of interest.

\section{References}

1 Slobody LB, Abramson H, Loizeaux,LS Jr: Agranulocytosis of the newborn infant. JAMA 1950;142:25.

2 Lehndorff, H: Transitorische Granulocytopenie beim Neugcborenen. Helv. Paediat. Acta. 1951;6:173.

3 Lalezari P, Nussbaum M, Gelman S, Spaet T: Neonatal neutropenia due to maternal immunization. Blood 1960;15:236-243.

4 Lalezari P, Radel E: Neutrophil-specific antigens: immunology and clinical significance. Semin Hematol 1974;11:281-290.

5 Lalezari P, Murphy GB, Allen FH Jr: NB1, a new neutrophil-specific antigen involved in the pathogenesis of neonatal neutropenia. J Clin Invest 1971;50:11081115.

6 Bux J: Nomenclature of granulocyte antigens. Transfusion 1999;39:662-663.

7 Flesch BK, Curtis BR, de Haas M, Lucas G, Sachs UJ Update on the nomenclature of human neutrophil antigens and alleles. Transfusion 2016;56:1477-1479.

8 Lalezari P, Spaet TH: Studies on the genetics of leukocyte antigens. Blood 1959;14:748.

9 Jiang AF, Lalezari P. A micro-technique for detection of leukocyte agglutinins. J Immunol Methods 1975;7: 103-108.

10 Verheugt FW, von dem Borne AE, Decary F, Engelfriet $\mathrm{CP}$ : The detection of granulocyte alloantibodies with an indirect immunofluorescence test. Br J Haematol 1977;36:533-544.

11 Bux J, Kober B, Kiefel V, Mueller-Eckhardt C: Analysis of granulocyte-reactive antibodies using an immunoassay based upon monoclonal-antibody-specific immobilization of granulocyte antigens. Transfus Med 1993;3:157-162.

12 Nguyen XD, Scherpf R, Sassenhof F, Flesch B, Klüter $\mathrm{H}$ : Detection of granulocyte antibodies using simultaneous analysis of specific granulocyte antibodies assay (SASGA). Vox Sang 2011;101:147-153.

13 Schulz U, Reil A, Kiefel V, Bux J, Moog R: Evaluation of a new microbeads assay for granulocyte antibody detection. Transfusion 2017;57:70-81.

14 Bux J, Behrens G, Jaeger G, Welte K: Diagnosis and clinical course of autoimmune neutropenia in infancy: analysis of 240 cases. Blood $1998 ; 91: 181-186$.

15 van den Tooren-de Groot R, Ottink M, Huiskes E, van Rossum A, van der Voorn B, Slomp J, de Haas M, Porcelijn L: Management and outcome of 35 cases with foetal/neonatal alloimmune neutropenia. Acta Paediatr 2014;103:e467-474.

16 Bux J, Jung KD, Kauth T, Mueller-Eckhardt C: Serological and clinical aspects of granulocyte antibodies leading to alloimmune neonatal neutropenia. Transfus Med 1992;2:143-149.

17 Middelburg RA, Porcelijn L, Lardy N, Briët E, Vrielink $\mathrm{H}$ : Prevalence of leucocyte antibodies in the Dutch donor population. Vox Sang 2011;100:327-335.
18 Middelburg RA, Vrielink H, Porcelijn L: Prevalence of granulocyte antibodies in never allo-exposed female and male donors. Eur J Haematol 2017;98:250-253.

19 Winkelhorst D, Oepkes D, Lopriore E: Fetal and neonatal alloimmune thrombocytopenia: evidence based antenatal and postnatal management strategies. Expert Rev Hematol 2017;10:729-737.

20 Kissel K, Hofmann C, Gittinger FS, Daniels G, Bux J: HNA-1a, HNA-1b, and HNA-1c (NA1, NA2, SH) frequencies in African and American Blacks and in Chinese. Tissue Antigens 2000;56:143-148.

21 Xia W, Simtong P, Santoso S: Neutrophil alloantigens and alloantibodies in different populations. ISBT Sci Se 2017;12:62-67.

22 Xia W, Ye X, Xu X, Chen D, Deng J, Chen Y, Ding H, Shao Y, Wang J, Liu J, Li H, Huang YF, Fu Y, Santoso S: The prevalence of leucocyte alloantibodies in blood donors from South China. Transfus Med 2015;25:385-392.

23 Huizinga TW, Kleijer M, Tetteroo PA, Roos D, von dem Borne AE: Biallelic neutrophil Na-antigen system is associated with a polymorphism on the phospho-inositol-linked Fc gamma receptor III (CD16). Blood 1990;75:213-217.

24 Bux J, Stein EL, Bierling P, Fromont P, Clay M, Stroncek D, Santoso S: Characterization of a new alloantigen (SH) on the human neutrophil Fc gamma receptor IIIb. Blood 1997;89:1027-1034.

25 Reil A, Sachs UJ, Siahanidou T, Flesch BK, Bux J: HNA-1d: a new human neutrophil antigen located on $\mathrm{Fc} \gamma$ receptor IIIb associated with neonatal immune neutropenia. Transfusion 2013;53:2145-2151.

26 Reil A, Flesch B, Bux J: FCGR3B ${ }^{\star} 04$ - a novel allele of the human Fc gamma receptor IIIb gene. Transfus Med Hemother 2011;38(suppl 1):p69.

27 de Haas M, Kleijer M, van Zwieten R, Roos D, von dem Borne AE: Neutrophil Fc gamma RIIIb deficiency, nature, and clinical consequences: a study of 21 individuals from 14 families. Blood 1995;86:2403-2413.

28 Bux J: Molecular genetics of granulocyte polymorphisms. Vox Sang 2000;78(suppl 2):125-130.

29 Flesch BK, Doose S, Siebert R, Ntambi E, Neppert J: FCGR3 variants and expression of human neutrophil antigen- $1 \mathrm{a},-1 \mathrm{~b}$, and $-1 \mathrm{c}$ in the populations of northern Germany and Uganda. Transfusion 2002;42:469-475.

30 Koene HR, Kleijer M, Roos D, de Haas M, Von dem Borne AE: Fc gamma RIIIB gene duplication: evidence for presence and expression of three distinct Fc gamma RIIIB genes in $\mathrm{NA}(1+, 2+) \mathrm{SH}(+)$ individuals. Blood 1998;91:673-679.

31 Nagelkerke SQ, Tacke CE, Breunis WB, Geissler J, Sins JW, Appelhof B, van den Berg TK, de Boer M, Kuijpers TW: Nonallelic homologous recombination of the FCGR2/3 locus results in copy number variation and novel chimeric FCGR2 genes with aberrant functional expression. Genes Immun 2015;16:422-429.
32 Kissel K, Santoso S, Hofmann C, Stroncek D, Bux J: Molecular basis of the neutrophil glycoprotein NB1 (CD177) involved in the pathogenesis of immune neutropenias and transfusion reactions. Eur J Immunol. 2001;31:1301-1309.

33 Kissel K, Scheffler S, Kerowgan M, Bux J: Molecular basis of NB1 (HNA-2a, CD177) deficiency. Blood 2002;99:4231-4233.

34 Wolff J, Brendel C, Fink L, Bohle RM, Kissel K, Bux J: Lack of NB1 GP (CD177/HNA-2a) gene transcription in NB1 GP-neutrophils from NB1 GP-expressing individuals and association of low expression with $N B 1$ gene polymorphisms. Blood 2003;102:731-733.

35 Moritz E, Chiba AK, Kimura EY, Albuquerque D, Guirão FP, Yamamoto $\mathrm{M}$, Costa FF, Bordin JO: Molecular studies reveal that A134T, G156A and G1333A SNPs in the CD177 gene are associated with atypical expression of human neutrophil antigen-2. Vox Sang 2010;98:160-166.

36 Greinacher A, Wesche J, Hammer E, Fürll B, Völker U, Reil A, Bux J: Characterization of the human neutrophil alloantigen-3a. Nat Med 2010;16:45-48.

37 Curtis BR, Cox NJ, Sullivan MJ, Konkashbaev A, Bowens K, Hansen K, Aster RH: The neutrophil alloantigen HNA-3a (5b) is located on choline transporter-like protein 2 and appears to be encoded by an R>Q154 amino acid substitution. Blood 20101;115:2073-2076.

38 Kline WE, Press C, Clay M, Keashen-Schnell M, Hackel E, McCullough J: Three sera defining a new granulocyte-monocyte-T-lymphocyte antigen. Vox Sang 1986;50:181-186.

39 Simsek S, van der Schoot CE, Daams M, Huiskes E, Clay M, McCullough J, van Dalen C, Stroncek D, von dem Borne AE: Molecular characterization of antigenic polymorphisms (Ond(a) and Mart(a)) of the beta 2 family recognized by human leukocyte alloantisera. Blood 1996;88:1350-1358.

40 Decary F, Verheugt FWA, van Helden-Henningheim L: Recognition of a non-HLA-ABC antigen present on $\mathrm{B}$ and $\mathrm{T}$ lymphocytes and monocytes only detectable with the indirect immunofluorescence test. Vox Sang 1982;36:150-158.

41 Sachs UJ, Reil A, Bauer C, Bux J, Bein G, Santoso S: Genotyping of human neutrophil antigen-5a (Ond). Transfus Med 2005;15:115-117.

42 Lopes LB, Abbas SA, Moritz E, Martins JO, Chiba AK, Langhi DM Jr, Bordin JO: Antibodies to human neutrophil antigen HNA-3b implicated in cases of neonatal alloimmune neutropenia. Transfusion 2018;58: 1264-1270.

43 Fung YL, Pitcher LA, Willett JE, Reed C, Mison L, Bux J, Eiber G, Minchinton RM: Alloimmune neonatal neutropenia linked to anti-HNA-4a. Transfus Med 2003;13:49-52. 
44 Curtis BR, Roman AS, Sullivan MJ, Raven CS, Larison J, Weitekamp LA: Two cases of maternal alloimmunization against human neutrophil alloantigen- $4 \mathrm{~b}$, one causing severe alloimmune neonatal neutropenia. Transfusion 2016;56:101-106.

45 Porcelijn L, Abbink F, Terraneo L, Onderwater-vd Hoogen L, Huiskes E, de Haas M: Neonatal alloimmune neutropenia due to immunoglobulin $\mathrm{G}$ antibodies against human neutrophil antigen-5a. Transfusion 2011;51:574-577.

46 Zupańska B, Uhrynowska M, Guz K, Maślanka K, Brojer E, Czestyńska M, Radomska I: The risk of antibody formation against HNAla and HNAlb granulocyte antigens during pregnancy and its relation to neonatal neutropenia. Transfus Med 2001;11:377-382.

47 Han TH, Chey MJ, Han KS: Granulocyte antibodies in Korean neonates with neutropenia. J Korean Med Sci 2006;21:627-632.

48 Curtis BR, Reno C, Aster RH: Neonatal alloimmune neutropenia attributed to maternal immunoglobulin $\mathrm{G}$ antibodies against the neutrophil alloantigen HNA-1c (SH): a report of five cases. Transfusion 2005;45:13081313.

49 Tomicic M, Starcevic M, Ribicic R, Golubic-Cepulic B, Hundric-Haspl Z, Jukic I: Alloimmune neonatal neutropenia in Croatia during the 1998-2008 period. Am J Reprod Immunol 2014;71:451-457.

50 Boxer LA, Bolyard AA, Kelley ML, Marrero TM, Phan L, Bond JM, Newburger PE, Dale DC: Use of granulocyte colony-stimulating factor during pregnancy in women with chronic neutropenia. Obstet Gynecol 2015; 125:197-203.

51 Manroe BL, Weinberg AG, Rosenfeld CR, Browne R: The neonatal blood count in health and disease. I. Reference values for neutrophilic cells. J Pediatr 1979;95: 89-98.

52 Schmutz N, Henry E, Jopling J, Christensen RD: Expected ranges for blood neutrophil concentrations of neonates: the Manroe and Mouzinho charts revisited. J Perinatol 2008;28:275-281.

53 Mouzinho A, Rosenfeld CR, Sanchez PJ, Risser R Revised reference ranges for circulating neutrophils in very-low-birth-weight neonates. Pediatrics 1994;94: 76-82.

54 Del Vecchio A, Christensen RD: Neonatal neutropenia: what diagnostic evaluation is needed and when is treatment recommended? Early Hum Dev 2012;88 (suppl 2):S19-24.
55 Maheshwari A: Neutropenia in the newborn. Curr Opin Hematol 2014;21:43-49.

56 Calhoun DA, Christensen RD, Edstrom CS, Juul SE, Ohls RK, Schibler KR, Sola MC, Sullivan SE: Consistent approaches to procedures and practices in neonatal hematology. Clin Perinatol 2000;27:733-753.

57 ISBT Working Party on Granulocyte Immunobiology, Bierling P, Bux J, Curtis B, Flesch B, Fung L, Lucas G, Macek M, Muniz-Diaz E, Porcelijn L, Reil A, Sachs U, Schuller R, Tsuno N, Uhrynowska M, Urbaniak S, Valentin N, Wikman A, Zupanska B: Recommendations of the ISBT Working Party on Granulocyte Immunobiology for leucocyte antibody screening in the investigation and prevention of antibody-mediated transfusion-related acute lung injury. Vox Sang 2009;96:266269.

58 Veldhuisen B, Porcelijn L, Ellen van der Schoot C, de Haas M: Molecular typing of human platelet and neutrophil antigens (HPA and HNA). Transfus Apher Sci 2014;50:189-199.

59 Dale DC: How I manage children with neutropenia. $\mathrm{Br}$ J Haematol 2017;178:351-363.

60 Kocherlakota P, La Gamma EF: Human granulocyte colony-stimulating factor may improve outcome attributable to neonatal sepsis complicated by neutropenia. Pediatrics 1997;100(1):E6.

61 Wiedl C, Walter AW: Granulocyte colony stimulating factor in neonatal alloimmune neutropenia: a possible association with induced thrombocytopenia. Pediatr Blood Cancer 2010;54:1014-1046.

62 Han TH, Chey MJ, Han KS: A case of neonatal alloimmune neutropenia associated with anti-human neutrophil antigen-1a (HNA-1a) antibody. J Korean Med Sci 2006;21:351-354.

63 Stroncek DF, Jaszcz W, Herr GP, Clay ME, McCullough J: Expression of neutrophil antigens after 10 days of granulocyte-colony-stimulating factor. Transfusion 1998;38:663-668.

64 Pocock CF, Lucas GF, Giles C, Vassiliou G, Cwynarski K, Rezvani K, Apperley JF, Goldman JM: Immune neutropenia associated with anti-human neutrophil antigen-2a (NB1) antibodies following unrelated donor stem cell transplantation for chronic myeloid leukemia: perpetuation by granulocyte colony-stimulating factor. Br J Hematol 2001;113:483-485.
65 Maheshwari A, Christensen RD, Calhoun DA: Resistance to recombinant human granulocyte colony-stimulating factor in neonatal alloimmune neutropenia associated with anti-human neutrophil antigen-2a (NB1) antibodies. Pediatrics 2002;109:e64.

66 Lee JA, Sauer B, Tuminski W, Cheong J, Fitz-Henley J 2nd, Mayers M, Ezuma-Igwe C, Arnold C, Hornik CP, Clark RH, Benjamin DK Jr, Smith PB, Ericson JE; Best Pharmaceuticals for Children Act - Pediatric Trials Network Steering Committee: Effectiveness of granulocyte colony-stimulating factor in hospitalized infants with neutropenia. Am J Perinatol 2017;34:458-464.

67 Aktaş D, Demirel B, Gürsoy T, Ovalı F: A randomized case-controlled study of recombinant human granulocyte colony stimulating factor for the treatment of sepsis in preterm neutropenic infants. Pediatr Neonatol 2015;56:171-175.

68 Carr R, Modi N, Doré C: G-CSF and GM-CSF for treating or preventing neonatal infections. Cochrane Database Syst Rev 2003;3:CD003066.

69 Chaudhuri J, Mitra S, Mukhopadhyay D, Chakraborty S, Chatterjee S: Granulocyte colony-stimulating factor for preterms with sepsis and neutropenia: a randomized controlled trial. J Clin Neonatol 2012;1:202206

70 Kuhn P, Messer J, Paupe A, Espagne S, Kacet N, Mouchnino G, Klosowski S, Krim G, Lescure S, Le Bouedec S, Meyer P, Astruc D: A multicenter, randomized, placebo-controlled trial of prophylactic recombinant granulocyte-colony stimulating factor in preterm neonates with neutropenia. J Pediatr 2009; 155:324-330.

71 Desenfants A, Jeziorski E, Plan O, Rodière M, Rimbert M, Muller JY, Taïb J, Cambonie G: Intravenous immunoglobulins for neonatal alloimmune neutropenia refractory to recombinant human granulocyte colonystimulating factor. Am J Perinatol 2011;28:461-466.

72 INIS Collaborative Group, Brocklehurst P, Farrell B, King A, Juszczak E, Darlow B, Haque K, Salt A, Stenson B, Tarnow-Mordi W: Treatment of neonatal sepsis with intravenous immune globulin. N Engl J Med 2011;365:1201-1211. 